\title{
A INOVAÇÃO TECNOLÓGICA E A FORMAÇÃO NAS HUMANIDADES
}

\author{
TECHNOLOGICAL INNOVATION AND THE FORMATION IN HUMANITIES \\ Juliane Marschall Morgenstern' e Marcio Paulo Cenci
}

\section{RESUMO}

O artigo discute a centralidade da inovação na gramática discursiva da educação contemporânea a fim de refletir sobre as possibilidades de inovar nas Humanidades. Para tanto, realizou-se uma historicização do campo das Humanidades mapeando a rede de sentidos em que o termo Humanidades emergiu e da qual provêm. Analisou-se que a primeira referência de "humanidade" remonta aos autores da Antiguidade Latina, quando o termo grego Paidéia é traduzido por Humanitas significando "filantropia", "cultura geral" ou "amor à humanidade". Já na tradição cristã, a expressão littera humaniores passa a ser utilizada para se referir aos textos laicos e distinguir-se dos textos de caráter sagrado. Nessa variação, destaca-se o uso do termo Humanidades pela Ordem dos Jesuítas, que o toma como campo de saber a ser ensinado. O uso do termo com esse sentido e a possibilidade de falar em ensino de Humanidades parece emergir com o modelo jesuíta e seu método escolástico. Tal modelo de ensino impactou as colônias espanholas nos séculos XVI ao XVIII e se coloca como uma das condições de possibilidade para a compreensão de ensino em Humanidades no presente. Diante do imperativo da inovação para o ensino de Humanidades na contemporaneidade, atentamos para o âmbito da formação. Formar pessoas não está desvinculado do ensino, mas o extrapola. As Humanidades constituem o campo do saber que assume, como condição básica, além da tarefa de instruir, a de formar pessoas para transformar o ser. Conclui-se, portanto, que a inovação nas Humanidades tem um papel mais fundamental que em outras áreas pois a produção do novo é mais radical e extrapola uma utilidade imediata. A inovação nas Humanidades requer o cultivo de um pensamento crítico, que ultrapassa o imediatismo, a padronização, a superficialidade, a banalização e a exclusão. Em sua finalidade, a formação em Humanidades pode encontrar meios para seu devir nas inovações tecnológicas, porém, tais inovações não são condições necessárias tampouco suficientes para inovar nas Humanidades.

Palavras-chave: Ensino; Educação; Filosofia.

\section{ABSTRACT}

This article discusses the centrality of innovation in the discursive grammar of contemporary education in order to reflect upon the position to innovate in the Humanities. To do so, it was carried out a historicization of the field of the Humanities, mapping out the meaning network in which the term Humanities emerged and from which it came. It was analyzed that the first reference to "humanity" goes back to the authors of Latin Classicism, when the Greek term Paidéia is translated to Humanitas meaning "philanthropy", "general culture" or "love for humanity".

1 Professora da Universidade Franciscana. Doutora em Educação pela UNISINOS. Mestre em Educação pela UFSM e graduada em Educação Especial e Pedagogia pela UFSM. E-mail: julianemm@ufn.edu.br

2 Professor da Universidade Franciscana. Doutor em Filosofia pela PUCRS. Mestre em Filosofia pela UFSM. Graduado em Filosofia pela UNOESC. E-mail: mpcenci@ufn.edu.br 
On the other hand, in Christian tradition, the expression littera humaniores comes to be used to refer to secular texts and it is used to be distinguished from texts of sacred nature. In such variation, one can highlight the use of the term Humanities by the Order of the Society of Jesus that takes such field of knowledge to be taught. The use of the term in this sense and the possibility of saying the teaching of Humanities seems to emerge with the Jesuit model and their scholastic method. Such model of teaching had repercussions on the Spanish colonies from XVI to the XVIII centuries and it is placed as one of the conditions of possibility to the comprehension of the teaching of Humanities nowadays. From the imperative of innovation to the teaching of humanities in contemporaneity, we attempt at the dimension of formation. The formation of people is not unattached to teaching but it extrapolates the formation itself. The Humanities constitute a knowledge field that assumes, as a basic condition, besides the task of instructing, the idea of forming people in order to transform the being. Therefore, one can conclude that innovation in the Humanities has a more fundamental role than in other areas because the production of the new if more radical and it extrapolates an immediate utility. Innovation in the Humanities requires the culture of critical thinking, that surpasses immediacy, standardization, superficiality, banalization and exclusion. In its goal, the formation of Humanities can find means to its becoming in technological innovation. However, such innovation are not necessary neither sufficient conditions to innovate the Humanities.

Keywords: Teaching; Education; Philosophy.

\section{INTRODUÇÃO}

Inovação é uma palavra que tem sido cada vez mais referenciada e utilizada em pesquisas e projetos de diferentes áreas. O conceito de inovação tem se mostrado variado e dependente, dentre outros aspectos, do modo como é aplicado. Se entendermos inovação como "exploração com sucesso de novas ideias", tal como nos apresenta a Inventta, companhia especializada em processos de inovação, poderíamos perguntar sobre 0 sucesso. Afinal, o que seria explorar com sucesso novas ideias? Para as empresas, sucesso pode ser o aumento de faturamento, o acesso a novos mercados ou o aumento das margens de lucro, entre outras possibilidades de expandir o negócio. Dentre as várias inovações que conhecemos e as possibilidades de fazer inovação, aquelas que se referem a inovações de produto ou de processo são conhecidas como inovações tecnológicas. Outros tipos de inovações também podem se relacionar a novos mercados, a novos modelos de negócio, a novos processos e métodos organizacionais ou, até mesmo, a novas fontes de suprimentos.

A inovação tecnológica tem estado presente não apenas nas formas de produção ou de expansão econômica da nossa sociedade, mas também tem marcado profundamente a nossa constituição subjetiva, tem afetado o modo como nos relacionamos uns com os outros e como nos relacionamos com nós mesmos. Nesse sentido, compreendemos que a revolução tecnológica já aconteceu e veio para ficar. Diante de tais mudanças, não queremos argumentar contra ou a favor da inovação ou da tecnologia. Entendemos que não nos cabe idolatrar ou refutar tais mudanças, mas perguntar sobre o que temos feito de nós mesmos a partir dessas transformações (HARARI, 2016; 2017). Assim, talvez seja oportuno nos perguntarmos sobre a vida que nós, seres humanos, queremos e podemos levar com e desde as inovações tecnológicas. Nessa direção, propomos uma reflexão sobre as possibilidades de inovação no campo das Humanidades, especialmente no que tange aos processos de ensino e de aprendizagem percebidos no presente. 
Voltando à inovação no campo tecnológico, de acordo com projeções do Fórum Econômico Mundial, em 2025, novas tecnologias terão sido integradas à rotina de parte da população mundial: 10\% das pessoas vão usar roupas conectadas à internet; 90\% da população mundial terá acesso à internet; 90\% da população usará smartphones; 5\% dos produtos de consumo estarão disponíveis para impressão 3D; 10\% dos carros nos Estados Unidos serão autônomos; e 30\% das auditorias serão realizadas por inteligência artificial. Se, em menos de dez anos, teremos mudanças com impacto significativo para a nossa vida, podemos imaginar que, em 40 ou 50 anos, teremos mudanças ainda maiores. Chegamos à Revolução 4.0, passando por outras três ou quatro grandes mudanças, ao considerarmos: a produção agrícola como mudança de impacto que aconteceu a mais ou menos 10 mil anos; seguida pela mecanização da produção, entre os anos de 1760 e 1830; pela eletricidade e pela manufatura em massa, aproximadamente em 1850; e pela revolução digital, já na metade do séc. XX, com a eletrônica, a tecnologia da informação e da telecomunicação.

Desse modo, vemos que a Revolução 4.0, diferente das anteriores, traz-nos a fusão de tecnologias promovendo a interação de distintos domínios, tal como o físico, o digital e o biológico. Essa conversão tecnológica, inigualável na história, mesmo em países desenvolvidos, anuncia significativas transformações nas formas de vida neste século. Marcada pela velocidade, profundidade e impacto sistêmico, a Revolução 4.0 nos coloca diante da mudança das questões do humano pela própria genética e pela intervenção de mecanismos corretivos no prolongamento e na manutenção da vida (HARARI, 2016; 2017).

Nessa direção, a inovação, como abertura ao novo, traz possibilidades de uma vida distinta para muitos de nós, permite-nos novas e diferentes experiências e pode trazer facilidades para a vida, seja no âmbito individual ou coletivo. Entretanto, a velocidade com que as mudanças têm afetado o mundo do trabalho e as relações torna urgente pensarmos sobre os efeitos dessas mudanças (LOPES, 2017). Para além das facilidades que a inovação tecnológica pode nos trazer, é preciso estarmos atentos ao que a novidade nos oferece em um prazo não imediato. Isso leva a um cuidado: não podemos confundir inovação e processos de inovação com melhoria ou com melhoria contínua. Se, no âmbito empresarial, as melhorias contínuas nem sempre são capazes de criar vantagens competitivas de médio e longo prazo, apesar de manterem a competitividade em relação ao custo, no que diz respeito aos aspectos educacionais, também não se pode afirmar que a inovação garanta alguma melhoria para os processos de ensino ou de aprendizagem.

Com isso, queremos dizer que a inovação tecnológica é condição necessária para que novas formas de vida sejam possíveis, mas não é condição suficiente. Nesse aspecto, fazemos referência a modos de viver distintos daqueles que até hoje conhecemos e que podem tornar a vida do corpo mais saudável e até melhor, em termos biológicos. Sem dúvida, um corpo saudável nos faz ter uma maior qualidade de vida, entretanto, cabe perguntar se esse avanço tecnológico seria suficiente sem uma formação que nos permita o cultivo de um tipo de existência que vale a pena ser vivida. A acelerada inovação tecnológica nos traz desafios tanto em relação aos efeitos dessas transformações para a vida em sociedade, quanto ao lugar ocupado pelas Humanidades nesse cenário (ORDINE, 2017).

Reiteramos nossa posição de não sermos contrários a qualquer forma de inovação, não é disso que se trata, o que almejamos é pontuar a necessidade de pensar a inovação no campo das Humanidades e, principalmente, a transversalidade que, a nosso ver, pode ser assumida pelas Humanidades no 
acompanhamento das transformações operadas pela tecnologia (LOPES, 2017; LOPES e MORGENSTERN, 2017). Se olharmos para as notícias veiculadas atualmente e para as falas de muitos professores, veremos que muitas apontam para a dificuldade desses profissionais em atualizar suas práticas pedagógicas de ensino. Tais narrativas dizem que os professores não estão acompanhando a velocidade da produção e a ampla circulação da informação. Nesse contexto, vemos inúmeros questionamentos em relação ao funcionamento e à própria existência da escola e nos questionamos: bastaria incorporarmos novos recursos tecnológicos, mantendo a escola, ou seria necessário pensar uma educação sem o tempo e sem o espaço escolares? (LOPES, 2017).

\section{O DESAFIO DE INOVAR NAS HUMANIDADES}

No espaço escolar, ao mesmo tempo em que os professores criticam os usos ilimitados da internet e a virtualização dos indivíduos, bem como tentam resistir a isso, também investem na busca de novas metodologias, capazes de manter a atenção dos alunos que chegam à escola constituídos por práticas que apontam o desejo insatisfeito de aprender novidades. Os professores se encontram entre duas perspectivas formativas: a da tradição disciplinar sólida e a da virtualização da vida, que tem como consequência a frugalidade das relações (LOPES, 2017; VEIGA-NETO, 2003). Portanto, conectada aos acontecimentos e tendências do presente, a escola tem sido tanto ativa na formação de um sujeito disciplinar quanto na formação de um sujeito conectado, que deve estar acessível a conexões (LOUREIRO, 2013).

Torna-se um desafio, portanto, a formação de um futuro profissional para o qual há muitas possibilidades em aberto, mas pouca ou nenhuma garantia de como irá atuar em determinada profissão. Nesse sentido, a formação nas Humanidades pode ser um diferencial para esses sujeitos, já que o domínio técnico de uma área não basta para tornar esse profissional alguém apto à necessária flexibilidade exigida pelo mercado. Quanto a isso, a inovação nas Humanidades não pode ser pensada do mesmo modo como pensamos a inovação em áreas mais tecnológicas, pois ela tem um papel mais fundamental, que vai além do conhecimento técnico (ORDINE, 2017). Por tais razões, as Humanidades não podem se restringir à produção de conhecimentos que estejam associados a uma futura utilidade técnica, uma utilidade palpável e imediata, sem se perguntar sobre a finalidade dessa utilidade. As Humanidades produzem uma utilidade de outra ordem, uma utilidade inútil (ORDINE, 2017), o que permite pensar o pensamento, pensar sem objetivo e pelo simples desejo de se exercitar. A eliminação desse pensamento pode acarretar padronização, superficialidade, banalização e exclusão.

Sendo assim, não podemos esquecer que, nas Humanidades, a utilidade pode ser de outra ordem que não a do uso imediato e, para alcançarmos essa outra finalidade, é preciso tempo livre, tempo de criação e experimentação. Afinal, nossa matéria-prima é a vida das pessoas, o que elas fazem com a vida, como conseguem perceber o mundo e existir também como profissionais, mas muito mais do que isso. Assim, a inovação que a formação nas Humanidades permite é mais radical para a forma como construímos o nosso pensamento e para a vida que levamos (LOPES e MORGENSTERN, 2017). A inovação nas Humanidades se encontra diante de diversos desafios, sem dúvida: o desafio das exigências do mundo do trabalho cada vez mais produtivista; o desafio de não ter tempo para o pensamento acontecer, para o novo emergir, para exercitar o pensamento, que é, por excelência, o seu laboratório de inovação. 
Considerando tais desafios, faremos uma breve digressão histórica para compreender a proveniência do campo das Humanidades, realizando, ainda, um contraste com as Ciências Humanas, a fim de traçar distinções importantes entre os campos de saber e de aprofundar a percepção acerca das Humanidades. Esse movimento de recuo nos permite realizar um tipo de historicização, a qual se volta às práticas que possibilitaram a instituição dos saberes e ao modo como foi se dando a composição do campo das Humanidades. Traçar uma história de inspiração genealógica nos pareceu interessante para a aproximação pretendida neste capítulo, qual seja, a formação em Humanidades e o desafio da inovação.

\section{A EMERGÊNCIA DO CAMPO DAS HUMANIDADES}

O campo das Humanidades emerge de modo problemático, ao menos, por duas razões. A primeira, de ordem etimológica, dado que não tem a mesma referência das Humanidades Clássicas. A segunda, de ordem histórica, denota uma forte aproximação das Humanidades com as Ciências Humanas, embora isso seja discutível, pois não há similitude quanto aos objetivos desses campos. O fato é que há um novo uso, nos últimos anos, que demarca um campo de atuação e interesse na educação, não exatamente conforme as ciências humanas e também não equivalente às Humanidades Clássicas, ainda que combine elementos dos dois sentidos. Além disso, embora ainda não seja conclusivo, podemos dizer que, na linguagem das instituições de fomento, a noção de Humanidades hoje começa a tomar o lugar da de Ciências Humanas.

O conceito de Humanidades emerge na tradição ocidental e, como tal, possui uma história de usos, revisões e abandonos (CHERVEL \& COMPÈRE, 1999). A primeira referência de "humanidade" remonta aos autores da Antiguidade Latina, como se nota em Cícero, no De Re Publica, I, XVII, 28, (1823, p. 68), quando traduz o termo grego Paidéia por Humanitas (HOGEL, 2015); e poderia significar "filantropia", "cultura geral" ou "amor à humanidade", como em Cícero, De Oratore, I, VIII, 31-34 (1942, p. 24). Esse conceito era utilizado para indicar o homem de bem, que teria a habilidade de se exprimir em público; ou mesmo aquele que seria formado para desempenhar bem seu papel de cidadão na administração da casa e da cidade.

Outra variação que o termo sofre se dá na tradição cristã, quando se usa a expressão littera humaniores para se referir aos textos laicos e criar a distinção das litterae divina ou sacra. Assim, por essa distinção terminológica, cria-se um conjunto de textos de caráter laico e outro de caráter sagrado. A absorção da tradição clássica, romana e grega, dá-se por um mecanismo de seleção dos textos que poderiam ser lidos como se fossem cristãos. Assim, os textos pagãos passam a ser ensinados como se fossem cristãos (CHERVEL \& COMPÈRE, 1999).

Nessa variação, há clara importância da Ordem dos Jesuítas que aplicaram o termo Humanidades a um campo do saber a ser ensinado. Este parece ser o primeiro uso do termo com esse sentido. No Ratio Studiorum (1599), nomearam de Humanidades os estudos intermediários entre os de Gramática e os de Retórica. Nota-se: "\$1. Número dos cursos inferiores. - As classes de estudos inferiores [...] não devem ser mais de cinco: uma de Retórica, outra de Humanidades e três de gramática". O objetivo do Ratio Studiorum é sintetizado por Franca (1952, p. 76): “[...] educar não é formar um homem abstrato intemporal, é preparar um homem concreto para viver no cenário deste mundo". Sob o aspecto da vida concreta neste 
mundo, a noção de Humanidades dos Jesuítas está profundamente conectada ao sentido do Humanitas dado por Cícero (CHERVEL \& COMPÈRE, 1999; HOGEL, 2015).

Esse modelo de ensino impactou as colônias espanholas nos séculos XVI ao XVIII. Isso porque o ensino das disciplinas das Humanidades seguia o método escolástico (REDMOND, 1972). Os textos fundamentais para as disciplinas básicas, como lógica, ética e metafísica, eram os textos de Aristóteles. O método escolástico era baseado no modelo de questões e comentários orientados pelas obras de Aristóteles e Tomás de Aquino (+1272) na Universidade de Salamanca. Entretanto, nas colônias, principalmente a Ordem Franciscana utilizou como modelo interpretativo o franciscano João Duns Scotus (+1306). Esse é um fator inovador nas colônias, dado que Scotus não era utilizado como orientador de interpretação nas universidades europeias, onde o método escolástico estava em decadência (PICH, 2011).

A produção intelectual seguiu de perto os métodos tradicionais das universidades europeias, principalmente, o método escolástico da Universidade de Salamanca. De fato, o ensino nas colônias hispânicas se desenvolveu, diferentemente das colônias portuguesas, em função de políticas imperialistas e de expansão cultural do Reino de Espanha (REDMOND, 1972). Contudo, esse movimento visava, ao menos no que se refere às colônias espanholas, a formação de pessoas conforme certo espírito espanhol. Essa formação foi concretizada pelos métodos de ensino que podem ser reconstruídos mediante a análise dos cursus philosophicus. Tal perspectiva de ensino se manteve pelo menos até o século XVIII nas colônias americanas.

De fato, o sentido tradicional de Humanidades, em seu núcleo semântico, faz referência à excelência dos escritores da Antiguidade, suas línguas e literaturas, para garantir a formação linguística (desenvolver a capacidade de se expressar claramente); a formação moral (as relações entre indivíduos e deles com o social); a formação patriótica e cívica (uma cultura que assegure a continuidade histórica da sociedade) (FRANCA, 1952; CHERVEL \& COMPÈRE, 1999).

As Humanidades nem sempre constituíram um campo claro de conhecimento. No geral, abarcavam estudos dos textos clássicos. A expressão Letras designava todos os saberes; mas, depois de 1720, passou a designar somente as obras literárias. A Literatura compreendia as obras do espírito, como a matemática, ao menos até fins do século XVIII, quando há uma mudança. E, quando a língua latina decai como língua oficial, a partir do século XVII, produz-se um distanciamento maior em relação às Humanidades clássicas. Outro ponto sobre a falta de clareza do sentido de Humanidades é que, no século XIX, na França, os colégios de Humanidades não ensinavam, por exemplo, Filosofia (CHERVEL \& COMPÈRE, 1999). Disso, deduz-se que a problemática do campo das Humanidades não é - e nem sempre foi - um campo homogêneo e disciplinar.

A emergência das Ciências Humanas e Sociais fez com que o conceito de Humanidades caísse em desuso. Durkheim trata as Ciências Humanas e Sociais como um saber científico, submetido a um método, e os cientistas devem ser educados nesse modelo. A criação destas Ciências induziu, invariavelmente, à especialização em função do método científico (DOMINGUES, 2004). Passou-se a compreender que, para um cientista, não se dava mais a aquisição de conhecimento pela leitura dos clássicos, como nas Humanidades, mas mediante uma educação entendida como científica, baseada na apropriação de um método científico adequado (CHERVEL \& COMPÈRE, 1999). Assim, as Humanidades foram colocadas em xeque.

Notamos como se sugeriu que, na contemporaneidade, há um processo de mudança na compreensão do escopo do campo das Humanidades. No século XXI, entre outras circunstâncias, uma marca dessa 
mudança está nas Humanidades se afirmarem como áreas de saber com conteúdos válidos ao ambiente universitário e escolar (MEIRINHOS, 2009). Isso fica evidente nos debates das últimas décadas para reafirmar as áreas de Artes, Filosofia e Sociologia como disciplinas específicas nos currículos escolares. Vejamos o que sugere Marcovitch (2002, p. 240): "Se entendemos a ciência como o domínio sistemático do saber, podemos dizer que ciência é tudo que se aprende nos bancos escolares, incluindo as Humanidades. [...] O ensino deve abranger todas as disciplinas, inclusive a arte." Entretanto, com as recentes mudanças no currículo do Ensino Médio, percebemos que essas e outras áreas disciplinares estão sendo transformadas em "[...] estudos e práticas <obrigatórias〉 de filosofia, sociologia, educação física e artes no ensino médio" (MEC, 2017). Utiliza-se a expressão "Ciências Humanas e Sociais Aplicadas" para designar esse campo, o que sugere um certo descompasso com a discussão contemporânea.

Se considerarmos esses argumentos, ainda que parciais e incompletos, é de se pensar que a manutenção do conceito de Humanidades sugere: (a) as Humanidades supõem um tipo de educação sem objetivo estritamente utilitário, pois propiciam acesso aos patrimônios humanos e à cultura geral (RIBEIRO, 2007); (b) elas são o campo propício para a interdisciplinaridade. (MEIRINHOS, 2009); (c) elas propiciam condições para equacionar múltiplas linguagens - poliglotismo cultural em oposição ao monoglotismo científico (MARCOVITCH, 2002); (d) e, por fim, constituem um conjunto de conhecimentos que permitem a interpretação do mundo (NUSSBAUM, 2015). Além disso, é importante considerarmos que há uma crítica ao sentido tradicional de Humanidades, que assumiria um viés humanista, ao considerar que ideias, normas, conceitos abarquem todos os humanos, indistintamente (BIESTA, 2013). No uso contemporâneo, as Humanidades se reconfiguram como espaço para a diversidade e a singularidade (NUSSBAUM, 2015).

Nesses termos, notamos que o desafio das Humanidades está alinhado ao da educação. As Humanidades, como um campo de saber que oferece um tipo de formação (ou transformaç̧ão do ser), dá acesso aos patrimônios da humanidade, para as pessoas se manterem abertas a interpretar (e viver) o modo de vida contemporâneo. Não é evidente a necessidade de distinção entre áreas disciplinares, dado que o instrumental conceitual e as práticas interpretativas orientam para o mesmo: a interpretação do mundo sob uma perspectiva complexa, a saber, não restrita a respostas unilaterais ou simplistas.

As Humanidades reafirmam a necessidade de uma formação como algo a ser ensinado. Formar pessoas não está desvinculado do ensino, mas o extrapola. As Humanidades constituem o campo do saber que assume, como condição básica, além da tarefa de instruir, a de formar pessoas, como sugere Biesta (2013), para (trans)formar o ser. Sendo assim, a tensão do contexto educacional atual coloca as práticas docentes em perspectiva com esse novo sentido das Humanidades. Esse sentido exige um conjunto de temas atuais acerca dos problemas do presente e do futuro, para uma interpretação do mundo consistente, realizada por qualquer cidadão. Por isso, esse ensino das Humanidades exige que os professores desenvolvam suas atividades de ensino de modo inovador e aberto, sendo também capazes de interpretar o mundo e a si mesmos (CAMARGO, CAMARGO, \& COSTA, 2016); (DINIZ-PEREIRA \& LACERDA, 2009). Entretanto, cabe ainda o problema que não é somente interpretativo, mas é resolutivo: como se pode avançar nas metodologias de ensino e aprimorar as práticas docentes nesse contexto de ensino e aprendizagem das Humanidades?

Como temos procurado mostrar, as tecnologias, sem dúvida, são importantes e acompanham a escola desde muito tempo - haja vista a utilização de caneta, lousa, papel, giz, cadeira, entre outros ma- 
teriais -, elas são instrumentos relevantes para que a educação aconteça, porém, seu uso não pode ser visto de forma isolada. A sua força de trabalho se encaixa com uma abordagem, um método de aplicação e com atos concretos. Aqui podemos falar de métodos de ensino e, mais particularmente, métodos que tanto geram interesse quanto abrem o mundo ou o apresentam" (MASSCHELEIN; SIMONS, 2013, p. 55). Muitos métodos ficam em nossa mente, como arquétipos, devido a seu caráter escolástico e, assim, têm uma importância significativa para nossa constituição subjetiva.

Entretanto, para além da utilização de métodos, processos ou recursos tecnológicos, inovar em educação e nas Humanidades requer tempo não apenas para o ensino, mas para a formação, uma formação que "tenha a ver com a orientação dos alunos para o mundo como ele é construído para existir no sujeito" (MASSCHELEIN; SIMONS, 2013, p. 47), uma orientação que se volte à atenção e ao interesse do sujeito para com o mundo e para com a própria pessoa em relação ao mundo. Trata-se de uma formação que permita a transformação, um novo sujeito constituído a partir da experiência, da atenção e da exposição a alguma coisa. De acordo com Masschelein e Simons (2013, p. 49), "a formação envolve, assim, sair constantemente de si mesmo ou transcender a si mesmo - ir além do seu próprio mundo da vida por meio da prática e do estudo". A formação torna-se, portanto, um movimento ativo de construção e reconstrução das subjetividades. Nesse cenário de formação ativa, é que podemos reconhecer os saberes das Humanidades como ocupando um lugar central.

Ao defender a escola ou o que é próprio do escolar, Masschelein e Simons (2013; 2014) nos dizem que a escola faz a provisão do tempo em que as necessidades e rotinas que ocupam a vida diária das crianças podem ser deixadas para trás. Assim, é um tipo de suspensão que constrói a escola, na qual os professores podem trabalhar sem a exigência de um ritmo produtivo. Nesse sentido, "podemos dizer que o tempo escolar é o tempo tornado livre e não é tempo produtivo" (MASSCHELEIN; SIMONS, 2013, p. 33) somente. Isso faz com que a escola não tenha o seu tempo domado em função de interesses estritamente econômicos ou produtivistas e, então, constitua-se como espaço de resistência. A possibilidade de criar uma brecha no tempo linear faz com que a escola também possa ser criadora de relações mais equânimes, na medida em que constrói tempo livre, removendo "expectativas, necessidades, papéis e deveres ligados a um determinado espaço fora da escola" (MASSCHELEIN; SIMONS, 2013, p. 37). O tempo para criação, sem um enquadramento prévio, coloca a formação na ordem do acontecimento e pode promover o pensamento divergente e a pluralidade nos modos de viver.

Se a nossa preocupação se volta à elaboração de novas práticas em educação escolar, também é preciso olharmos com mais atenção para o fazer cotidiano dos professores. É no saber de experiência que podemos ver novas práticas se desenharem, funcionando como algo que pode ser inovador para a educação. Nesse sentido, é preciso que nós, professores, mantenhamo-nos atentos para a inovação que pode decorrer dos conhecimentos pedagógicos e de nossa ação cotidiana, visando a qualificar, cada vez mais, as práticas de ensino e a formação de nossos alunos. Além de tudo, também é importante fazermos o registro de tais práticas para compartilhá-las e pensá-las coletivamente.

Cabe a nós considerarmos que os saberes remetem a um campo prático de exercício da docência, aos modos como se ensina ou como se poderia ensinar, e não somente ao Saber da Pedagogia, da Didática ou do Ensino como campo de conhecimento disciplinar que existiria de forma desvinculada do fazer-ensinar. Dessa perspectiva, aquilo que um professor deve saber ensinar não constitui um problema 
cognitivo ou epistemológico apenas, mas uma questão social, já que está envolvido com a transformação, a educação e instrução dos alunos. Em outras palavras, pode-se dizer que a construção de novos conhecimentos, derivados dos saberes da experiência docente, condiz com uma elaboração coletiva, assim como o debate e a negociação em torno daquilo que os professores devem saber ensinar. Assim, é neste fazer-ensinar que são vistas novas práticas se desenharem, tornando possível inovar na educação e no ensino de Humanidades.

\section{REFERÊNCIAS}

BIESTA, G. Para além da aprendizagem: educação democrática para um futuro humano. Coleção Educação: Experiência e Sentido. Belo Horizonte: Autêntica, 2013.

Medir lo que valoramos o valorar lo que medimos? Globalización, responsabilidad y la noción de propósito de la educación. Pensamiento Educativo. Revista de Investigación Educacional Latinoamericana, v. 1, n. 51, p. 46-57, 2014.

BRASIL, MEC. Novo Ensino Médio - DúvIDAS, 2017. Disponivel em: Novo Ensino Médio - DúVIDAS. Acesso em: 01 Março 2017.

CAMARGO, J. S.; CAMARGO, L. S.; COSTA, L. P. D. Uso da TV PENDRIVE ou TV MULTIMÍDIA na Educação Básica. Simpósio Internacional de Educação a Distância e Encontro de Pesquisadores em Educação a Distância. São Carlos: UFSCAR. 2016. p. 01-15.

CASTEL, R. As metamorfoses da questão social. Petrópolis: Vozes, 1998.

CHERVEL, A.; COMPÈRE, M.-M. As humanidades no ensino. Educação e Pesquisa, São Paulo, 25, n. 2, Jul.-Dez. 1999. p. 149-170.

DINIZ-PEREIRA, J. E.; LACERDA, M. P. D. Possíveis significados da pesquisa na prática docente: ideias para fomentar o debate. Educação e Sociedade, Campinas, 30, n. 109, Set.-Dez. 2009. p. 1229-1242.

DOMINGUES, I. Epistemologia das ciências humanas (Tomo I: Positivismo e hermenêutica: Durkheim e Weber). São Paulo: Edições Loyola, 2004. 671 p.

FRANCA, L. 0 método pedagógico dos jesuítas: o "Ratio Studiorum": Introdução e Tradução. Rio de Janeiro: Agir Editora, 1952.

HARARI, Y. N. Homo deus: uma breve história do amanhã. Tradução Paulo Geiger. 1. ed. São Paulo: Companhia das Letras, 2016.

Sapiens: uma breve história da humanidade. Tradução Janaína Marcoantonio. 25. ed. Porto Alegre, RS: L\&PM, 2017.

HOGEL, C. The Human and the Humane: Humanity as Argument from Cicero to Erasmus. Goettingen: Vandenhoeck \& Ruprecht, 2015. 
LOPES, M. C. A escola tem futuro? A (in)utilidade dos saberes das humanidades e a exclusão. Conferência de encerramento do I Congresso Internacional de Educaciones, Pedagogías y Didacticas. 2017. Realizado nos dias 14, 15 e 16 de setembro de 2017, na Universidad Pedagógica y Tecnológica de Colombia (UPTC).

LOPES, M. C; MORGENSTERN, J. M. As humanidades frente aos desafios tecnocientíficos contemporâneos. In: Thaumazein, Santa Maria, v. 10, n. 20. 2017. 93-100.

LOUREIRO, C. B. Disseminação das tecnologias digitais e promoção da inclusão digital na educação pública: estratégias da governamentalidade eletrônica. 2013. 210 f. Tese (Doutorado em Educação) Programa de Pós-Graduação em Educação, Universidade do Vale do Rio dos Sinos - UNISINOS, São Leopoldo, 2013.

MARCOVITCH, J. Os desafios da área de Humanidades no Brasil e no mundo. Estudos Avançados, 14, n. $46,2002.233-243$.

MASSCHELEIN, J; SIMONS, M. Em defesa da escola: uma questão pública. Tradução Cristina Antunes. Belo Horizonte: Autêntica, 2013.

A pedagogia, a democracia, a escola. Belo Horizonte, MG: Autêntica, 2014.

MEIRINHOS, J. Universidade e conhecimento. O lugar das Humanidades. Biblioteca Digital - Faculdade de Letras. Universidade do Porto, PORTO, 2009. Disponivel em: https://bit.ly/306jYig. Acesso em: 25 Setembro 2016.

NUSSBAUM, M. Sem fins lucrativos: por que a democracia precisa das humanidades. São Paulo: WMF Martins Fontes, 2015.

ORDINE, N. É preciso transformar a educação em uma forma de resistência à barbárie do lucro. 2017. Disponível em: https://glo.bo/3uPkjnm. Acesso em 10 de nov. 2017.

PICH, R. H. Notas sobre Jerónimo Valera e suas obras sobre Lógica. Cauriensia, VI, 2011, p. 169-202.

REDMOND, W. B. Bibliography of the Philosophy in the Iberian Colonies of America. Nijhoff: The Hague, 1972.

RIBEIRO, R. J. Entrevista com Renato Janine Ribeiro. Humanidades em Diálogo, 1, n. 1, Nov. 2007. p. 17-33.

VEIGA-NETO, A. A arte de viver e educação escolar: caminhos, conexões, impasses. In: PAGNI, Pedro Angelo; BUENO, Sinésio Ferraz; GELAMO, Rodrigo Pelloso (org.). Biopolítica, arte de viver e educação. Marília: Oficina Universitária; São Paulo: Cultura Acadêmica, 2012. p. 195-214.

Pensar a escola como uma instituição que pelo menos garanta a manutenção das conquistas fundamentais da modernidade. In: COSTA, M. V. (Org). A escola tem futuro? Rio de Janeiro: DP\&A, 2003. p. 103-126. 